\title{
Oxidative Stability of Avocado and Peanut Oils Under Different Heating Temperatures
}

\author{
FLAVIA POP ${ }^{*}$, CRISTINA ANAMARIA SEMENIUC ${ }^{2}$ \\ ${ }^{1}$ Technical University of Cluj-Napoca, North University Center of Baia Mare, Chemistry and Biology Department, 76A \\ Victoriei Str., 430122, Baia Mare, Romania \\ ${ }^{2}$ University of Agricultural Sciences and Veterinary Medicine of Cluj-Napoca, Department of Food Engineering, 3-5 \\ Mănăştur Str., 400372, Cluj-Napoca, Romania
}

\begin{abstract}
The objective of this research was to investigate the effect of heating temperature on the quality parameters of avocado and peanut oils subjected to heating. Vegetable oils were heated at varying temperatures (110, 140, 170, 200 and $230^{\circ} \mathrm{C}$ for $\left.30 \mathrm{~min}\right)$ to follow quality alterations. Levels of peroxide value, iodine value, thiobarbituric acid reactive substances, total polar compounds, refractive index, free acidity, and fatty acids composition were determined to measure the extent of lipid oxidation. Peroxide value was significantly $(p<0.001)$ influenced by heating temperature in the case of peanut oil. Iodine value decreased significantly $(p<0.01)$ in both oils with the increase in heating temperature due to the decrease of the unsaturation degree. Avocado oil showed the smallest increase in thiobarbituric acid reactive substances and total polar compounds during heat treatment. The fatty acids profile of peanut oil was rich in polyunsaturated fatty acids with a level of $42 \%$, followed by monounsaturated fatty acids with about 36\%. The heat treatment of oils has produced changes in unsaturated fatty acids, these have undergone isomerization from cis to trans form. The increases of heating temperature up to $230^{\circ} \mathrm{C}$ significantly deteriorated the quality of peanut oil, but to a lesser extent the one of avocado oil.
\end{abstract}

Keywords: avocado oil, peanut oil, heating, fatty acids profile, polar compounds

\section{Introduction}

Vegetable oils have energy benefits and are necessary for the normal functioning of the body, lipids being the structural constituents of the body's cells. Consumed in a moderate amount, these are an essential and healthy component of our daily diet [1].

Due to the widespread use of frying oils, the effect of high temperatures on these is of great concern both for their quality and nutritive value. At high frying temperatures, oils are subjected to numerous chemical reactions. These affect the flavour of the fried product and the quality of the frying oil. The taste, flavour, lifetime, and consumer acceptance of fried product are related to the frying oil quality [25].

Avocado oil is an edible oil obtained by Persea americana fruits pressing. It is rich in monounsaturated fats, vitamin E, and contains more protein than any other fruit and more potassium than a banana [6]. According to a study by Unlu et al. (2005), avocado oil increases the absorption of carotenoids from food [7]. A study on laboratory animals has shown that a diet rich in avocado oil affects the level of essential fatty acids in kidneys, which leads to changes in the way the kidneys respond to hormones that lower blood pressure, and thus lowers blood pressure [8]. In a study of guinea pigs, the authors studied the atherogenic effects of avocado oil versus coconut, olive and corn oils. Avocado oil has proven to be the best in fighting atherosclerosis [9]. Berasategi et al. (2012), have reported that avocado and soybean oils may be helpful in treating periodontal disease, reducing inflammation, and inhibiting pro-inflammatory cytokines [10].

Some studies have shown that consumption of peanut oil, which is rich in resveratrol, can reduce the risk of developing cancer, due to its antioxidant properties [11-13]. Also, it reduces blood pressure, prevents cognitive impairment, and stimulates the immune system [14-16].

\footnotetext{
*email: flavia_maries@yahoo.com
} 
Temperature can cause many physical and chemical changes in all food constituents. The mainly modifications which appear during the heating process of the fats are owed to the oxidation process [17, 18]. Oxidation of food is responsible for the degradation of sensory qualities, the decrease of the nutritional value, and the formation of free radicals and toxic substances such as peroxides [19].

Thermal oxidation of oils occurs as a self-oxidation reaction, through the formation of free radicals. In the first stage, the reaction is initiated by the loss of a proton and the formation of an alkyl radical $(\mathrm{R} \cdot)$. In the propagation step, the radical binds oxygen and form a peroxy radical (R-O-O·). Termination of the reaction involves the recombination of radicals with the formation of stable compounds such as: hydroperoxides, epoxies, epidioxides, hydroperoxy-epidioxides, etc. [20-22]. The autooxidation process of oils is accelerated by the following factors: temperature, heavy metals, the presence of oxygen, the fatty acids degree of unsaturation, wavelength of light radiation, the absence of self-oxidation inhibitors like natural or added antioxidants [23, 24].

In some studies it has been reported the influence of heating on vegetable oils quality $[25,26]$, the degradation of fatty acids and bioactive compounds during thermal treatment [27, 28], sensorial modifications [29], and also rheological and physical changes [30, 31].

The purpose of this research was to investigate the effect of temperature $(110,140,170,200$ and $230^{\circ} \mathrm{C}$ for $30 \mathrm{~min}$ ) on the quality of avocado and peanut oils by analysing PV (peroxide value), IV (iodine value), TBARS (thiobarbituric acid reactive substances), TPC (total polar compounds), refractive index (RI), acid value (AV), and fatty acids content. There is a lack of systematic studies for evaluating the oxidative stability of avocado and peanut oils. This is the first study examining the extent of lipid oxidation in these oils.

\section{Materials and methods}

\subsection{Samples}

To monitor the behavior under heating conditions, avocado and peanut oils were procured from the local market. Approximately $50 \mathrm{~mL}$ of oil were transferred into a glass tube (an exposure area to the air of $80 \mathrm{~cm}^{2}$ ) and subjected to heating in an electric oven at $110,140,170,200$, and $230^{\circ} \mathrm{C}$ for $30 \mathrm{~min}$. After cooling, samples were stored under refrigeration until analysis. For each studied oil, unheated oil was used as the control sample.

Peroxide value (PV) was determined using a UV-VIS T60U spectrophotometer. A test portion was dissolved in a mixture of chloroform/methanol $(2: 1, \mathrm{v} / \mathrm{v})$, then iron(II) chloride and ammonium thiocyanate were added. The peroxides in the sample oxidize the iron(II) ions to iron(III). Ammonium thiocyanate forms with iron(III) a red complex. The absorbance of each sample was read at $500 \mathrm{~nm}$ against blank. To quantify the peroxides in the sample, a calibration curve was constructed using iron(III) chloride. The PV has been expressed as meq $\mathrm{O}_{2} / \mathrm{kg}$ oil.

To determine the iodine value (IV) was used the Hanus method described by Pop (2018) and was expressed as $\mathrm{g} \mathrm{I}_{2} / 100 \mathrm{~g}$ oil [32].

Thiobarbituric acid reactive substances (TBARS) test was carried out based on the method described by Semeniuc et al. (2016). One gram of sample was weighed into a test tube with glass stoppered. Then, $5 \mathrm{~mL}$ of TBA reagent was added (0.02 M 2-thiobarbituric acid in $90 \%$ glacial acetic acid) and homogenized. A blank sample was prepared with distilled water and TBA reagent and treated as the sample. After heating, the sample was cooled in tap water for $10 \mathrm{~min}$. The optical density of the sample was read against the blank at $538 \mathrm{~nm}$ using a UV-VIS T60U spectrophotometer. A standard curve was prepared by making appropriate dilutions of the $1 \times 10^{-3} \mathrm{M}$ 1,1,3,3-tetraethoxypropane standard solution, to give amounts ranging from $1 \times 10^{-8}$ to $7 \times 10^{-8} \mathrm{~mol}$ malondialdehyde $(\mathrm{MDA}) / \mathrm{mL}$. These were reacted with TBA reagent and their optical densities were measured at $538 \mathrm{~nm}$. TBARS value was expressed as mg MDA/kg sample [33].

The measurement of total polar compounds (TPC) was carried out using a cooking oil tester (Testo 265, Testo, Inc., Sparta, USA).

Refractive index (RI) was determined by using the PAL-RI (Tokyo, Japan) refractometer. 
Determination of acid value (AV) consisted of neutralization of sample acidity with sodium hydroxide solution $0.1 \mathrm{~N}$ using phenolphthalein as an indicator. It was expressed as $\mathrm{g}$ oleic acid/100 $\mathrm{g}$ oil [32].

To determine the fatty acids composition, a Shimadzu GC-17 A gas chromatograph (Tokyo, Japan) coupled with flame ionization detector was used. It was equipped with Alltech AT-Wax (60 m x 0.32 $\mathrm{mm} \times 0.5 \mu \mathrm{m})$ gas chromatographic column with a polyethylene stationary phase. The injector and detector temperature was set to $260^{\circ} \mathrm{C}$. Fatty acids were identified and quantified by comparison with standards. The results were expressed as percentage [32].

The reagents used were of analytical grade and purchased from Merck (Germany). The determinations were conducted in triplicate and values of parameters were calculated as the mean of replicates. Tukey's honest significance test was carried out at a 95\% confidence level $(p<0.05)$. Pearson's correlation $(a=0.05)$ was used to estimate the strength of association between chemical parameters.

\section{Results and discussions}

Values for PV, IV, TBARS, TPC, RI, and AV are shown in Table 1 and Table 2.

Unheated oils showed lower levels of PV. The peroxide index level was higher in peanut oil than in avocado oil. Peroxide value was significantly $(p<0.001)$ influenced by heating temperature in the case of peanut oil. Regardless of heating temperature, the lowest PV was found in avocado oil (Table 1). In the case of peanut oil, the most intensive formation of peroxides was found to be at $200^{\circ} \mathrm{C}$. Above this temperature, their decomposition was dominant (Table 2). A cause of this trend may be that peroxides are not heat-resistant, and the high temperature lowers their concentration. Results showed that avocado oil was more stable to heating and produced smaller amounts of peroxides.

Santana et al. (2014) investigated the influence of drying and extraction method on the quality of Hass avocado oil. This study showed that oil from pressed and microwave-dried avocado pulp presented the lowest PV and AV, therefore the highest oxidative and hydrolytic stability compared to the oil extracted with ethanol. The fatty acid composition did not differ significantly $(p>0.05)$ between the processes. These researchers concluded that pressing avocado pulp, dried under microwaves, stands out as a promising alternative for avocado oil processing that is appropriate for consumption as edible oil [34]. Bogatu et al. (2016) have evaluated the behaviour of vegetable and mineral oils mixed with suitable antioxidant additive. Results showed a significantly different behaviour of the additive mixed with the two oil categories, behaviour that could be explained in correlation with their specific chemical structure [35].

Iodine value decreased significant $(p<0.01)$ with the increase in heating temperature for both oils, due to the reduction of the unsaturation degree, and the split of unsaturated double bonds from fatty acids. IV decreased from 99.1 to $91.3 \mathrm{~g} \mathrm{I}_{2} / 100 \mathrm{~g}$ in avocado oil, and from 89.7 to $79.5 \mathrm{~g} \mathrm{I}_{2} / 100 \mathrm{~g}$ in peanut oil subjected to heating at varying temperatures. It was found a direct correlation between the IV and the RI values $(r=0.95)$.

Thiobarbituric acid reactive substances test is a measure of the number of oxidation by-products (aldehydes, ketones, or other matrix compounds) present in the oil sample. Like PV, TBARS values increased significantly $(p<0.001)$ with heating temperature in peanut oil. TBARS increased from 1.18 to $7.60 \mathrm{mg} \mathrm{MDA} / \mathrm{kg}$ in avocado oil subjected to heating at varying temperatures, and from 2.07 to 9.48 $\mathrm{mg}$ MDA $/ \mathrm{kg}$ in peanut oil subjected to heating (Tables 1,2 ).

The limit of $8 \mathrm{mg}$ MDA $/ \mathrm{kg}$ for TBARS was exceeded in peanut oil subjected to heating at $230^{\circ} \mathrm{C}$. Heating temperature significantly $(p<0.001)$ influenced the TBARS values in peanut oil. Between PV and TBARS were found strong positive correlations in avocado $(r=0.96 ; p<0.01)$ and peanut oil $(r=$ 0.94; $p<0.001)$. 
Table 1. Changes in quality parameters of avocado oil during heating

\begin{tabular}{|c|c|c|c|c|c|c|}
\hline \multirow{2}{*}{$\begin{array}{c}\text { Heating } \\
\text { temperature }\end{array}$} & \multicolumn{9}{|c|}{ Avocado oil } \\
\cline { 2 - 7 } & $\begin{array}{c}\text { PV } \\
(\mathrm{meq} \mathrm{O} / \mathrm{kg})\end{array}$ & $\begin{array}{c}\text { IV } \\
(\mathrm{g} \mathrm{I} / 100 \mathrm{~g})\end{array}$ & $\begin{array}{c}\text { TBARS } \\
(\mathrm{mg} \mathrm{MDA} / \mathrm{kg})\end{array}$ & TPC (\%) & $\begin{array}{c}\text { RI (refractometric } \\
\text { degrees) }\end{array}$ & $\begin{array}{c}\mathrm{AV} \\
(\mathrm{g} \mathrm{oleic} \mathrm{acid} / 100 \mathrm{~g})\end{array}$ \\
\hline Unheated & $2.16^{\mathrm{a}}$ & $99.1^{\mathrm{a}}$ & $1.18^{\mathrm{a}}$ & $2.1^{\mathrm{a}}$ & $1.4856^{\mathrm{a}}$ & $0.16^{\mathrm{a}}$ \\
\hline $110^{\circ} \mathrm{C}$ & $3.02^{\mathrm{b}}$ & $98.3^{\mathrm{a}}$ & $2.41^{\mathrm{ab}}$ & $5.9^{\mathrm{c}}$ & $1.4849^{\mathrm{a}}$ & $0.27^{\mathrm{ab}}$ \\
\hline $140^{\circ} \mathrm{C}$ & $4.85^{\mathrm{c}}$ & $97.4^{\mathrm{b}}$ & $3.54^{\mathrm{b}}$ & $9.2^{\mathrm{d}}$ & $1.4837^{\mathrm{b}}$ & $0.41^{\mathrm{b}}$ \\
\hline $170^{\circ} \mathrm{C}$ & $5.74^{\mathrm{d}}$ & $95.1^{\mathrm{bc}}$ & $5.12^{\mathrm{c}}$ & $13.9^{\mathrm{e}}$ & $1.4800^{\mathrm{bc}}$ & $0.63^{\mathrm{bc}}$ \\
\hline $200^{\circ} \mathrm{C}$ & $7.65^{\mathrm{e}}$ & $92.2^{\mathrm{c}}$ & $6.05^{\mathrm{d}}$ & $16.8^{\mathrm{f}}$ & $1.4763^{\mathrm{c}}$ & $0.71^{\mathrm{c}}$ \\
\hline $230^{\circ} \mathrm{C}$ & $8.92^{\mathrm{f}}$ & $91.3^{\mathrm{d}}$ & $7.60^{\mathrm{e}}$ & $20.7^{\mathrm{g}}$ & $1.4732^{\mathrm{cd}}$ & $0.85^{\mathrm{d}}$ \\
\hline$p$ & $<0.01$ & $<0.01$ & $<0.01$ & $<0.001$ & $<0.05$ & $<0.01$ \\
\hline
\end{tabular}

a) PV, peroxide value; IV, iodine value; TBARS, thiobarbituric acid reactive substances; TPC, total polar compounds; RI, refractive index; $\mathrm{AV}$, acid value.

b) Values are expressed as mean.

c) Different letters in the same column indicate statistically significant differences (Tukey's test $p<0.05$ ).

d) Significant differences are denoted by asterisks: ${ }^{*} p<0.05 ; * p<0.01 ; * * *<0.001 ; p \geq 0.05$, non-significant.

Table 2. Changes in quality parameters of peanut oil during heating

\begin{tabular}{|c|c|c|c|c|c|c|}
\hline \multirow{2}{*}{$\begin{array}{c}\text { Heating } \\
\text { temperature }\end{array}$} & \multicolumn{6}{|c|}{ Peanut oil } \\
\cline { 2 - 7 } & $\begin{array}{c}\mathrm{PV} \\
\left(\mathrm{meq} \mathrm{O}_{2} / \mathrm{kg}\right)\end{array}$ & $\begin{array}{c}\mathrm{IV} \\
(\mathrm{g} \mathrm{I} / 100 \mathrm{~g})\end{array}$ & $\begin{array}{c}\text { TBARS } \\
(\mathrm{mg} \mathrm{MDA} / \mathrm{kg})\end{array}$ & TPC (\%) & $\begin{array}{c}\text { RI (refractometric } \\
\text { degrees) }\end{array}$ & $\begin{array}{c}\text { AV } \\
(\mathrm{g} \text { oleic acid/100 } \\
\mathrm{g})\end{array}$ \\
\hline Unheated & $2.35^{\mathrm{a}}$ & $89.7^{\mathrm{a}}$ & $2.07^{\mathrm{a}}$ & $3.7^{\mathrm{a}}$ & $1.4967^{\mathrm{a}}$ & $0.22^{\mathrm{a}}$ \\
\hline $110^{\circ} \mathrm{C}$ & $3.67^{\mathrm{b}}$ & $88.5^{\mathrm{a}}$ & $3.92^{\mathrm{b}}$ & $7.2^{\mathrm{c}}$ & $1.4951^{\mathrm{a}}$ & $0.38^{\mathrm{ab}}$ \\
\hline $140^{\circ} \mathrm{C}$ & $5.04^{\mathrm{c}}$ & $87.3^{\mathrm{b}}$ & $5.13^{\mathrm{c}}$ & $11.4^{\mathrm{e}}$ & $1.4912^{\mathrm{b}}$ & $0.57^{\mathrm{b}}$ \\
\hline $170^{\circ} \mathrm{C}$ & $6.28^{\mathrm{d}}$ & $86.1^{\mathrm{c}}$ & $6.34^{\mathrm{d}}$ & $16.5^{\mathrm{f}}$ & $1.4893^{\mathrm{c}}$ & $0.74^{\mathrm{c}}$ \\
\hline $200^{\circ} \mathrm{C}$ & $9.72^{\mathrm{e}}$ & $81.6^{\mathrm{d}}$ & $7.86^{\mathrm{e}}$ & $21.3^{\mathrm{g}}$ & $1.4852^{\mathrm{cd}}$ & $0.83^{\mathrm{d}}$ \\
\hline $230^{\circ} \mathrm{C}$ & $8.11^{\mathrm{ef}}$ & $79.5^{\mathrm{de}}$ & $9.48^{\mathrm{f}}$ & $25.2^{\mathrm{h}}$ & $1.4826^{\mathrm{d}}$ & $0.96^{\mathrm{de}}$ \\
\hline$p$ & $<0.001$ & $<0.01$ & $<0.001$ & $<0.001$ & $<0.05$ & $<0.01$ \\
\hline
\end{tabular}

a) PV, peroxide value; IV, iodine value; TBARS, thiobarbituric acid reactive substances; TPC, total polar compounds; RI, refractive index; $\mathrm{AV}$, acid value.

b) Values are expressed as mean.

c) Different letters in the same column indicate statistically significant differences (Tukey's test $p<0.05$ ).

d) Significant differences are denoted by asterisks: $* p<0.05 ; * p<0.01 ; * * * p<0.001 ; p \geq 0.05$, non-significant.

Sun-Waterhouse et al. (2011) investigated the effects of added phenolics (caffeic acid and $p$ coumaric acid) on the storage stability of avocado and coconut oils. The study showed that storage at $60^{\circ} \mathrm{C}$ accelerated oil oxidation and the caffeic acid or $p$-coumaric acid helped preserve avocado and coconut oils to different extents. Caffeic acid and $p$-coumaric acid also protected some desirable unsaturated fatty acids at $60^{\circ} \mathrm{C}$ but facilitated the hydrolysis of triglycerides [36].

Polar compounds include all oxidized triglycerides, dimerized triglycerides, free fatty acids, diglycerides, monoglycerides, sterols, antifoams, hydrogenation catalyst residues and soaps formed during repeated heating of oils. In peanut oil it was noticed a fast increase of TPC, indicating the oil deterioration during heating at $230^{\circ} \mathrm{C}$, but avocado oil was more stable.

If the total polar compounds overcome $24 \%$, the oil should be disposed of according to Lozano et al. (1998) [26]. It is observed from Table 2, that the total polar compound values exceeded $24 \%$ when peanut oil was heated at $230^{\circ} \mathrm{C}$. TPC is found to be $20.7 \%$ for avocado oil and $25.2 \%$ for peanut oil subjected to heating at $230^{\circ} \mathrm{C}$, indicating the deterioration of peanut oil.

$\mathrm{RI}$ is a measure of the degree of fatty acids unsaturation. In peanut oil was determined a higher value of RI compared to avocado oil and with the increase in heating temperature it was observed that RI values decreased significant $(p<0.05)$ for all samples.

Free acidity is used to evaluate the extension of oil hydrolysis during the heating process. AV increased from 0.16 to $0.85 \mathrm{~g}$ oleic acid $/ 100 \mathrm{~g}$ in avocado oil and from 0.22 to $0.96 \mathrm{~g}$ oleic acid/100 $\mathrm{g}$ in 
peanut oil subjected to heating at varying temperatures. Acid value was significantly $(p<0.01)$ influenced by the heating temperature.

The fatty acids that enter the structure of vegetable glycerides belong to saturated and unsaturated monocarboxylic acids, with an even number of carbon atoms in the molecule, distributed in normal and sometimes cyclic chains. The fatty acids profile of peanut oil was rich in oleic (C18:1), eicosenoic (C20:2), eicosapentaenoic (C20:5), arachidonic (C20:4), palmitic (C16:0) and alpha-linolenic (C18:3) acids. The palmitoleic (C16:1) and vaccenic acid (C18:1 $1_{\mathrm{i}}$ ) amounts were also important (Figure 1).

The fatty acids profile for unheated and oils subjected to heating at $230^{\circ} \mathrm{C}$ is reported. The fatty acids profile of avocado oil contained in a higher amount oleic $(\mathrm{C} 18: 1)$, linoleic $(\mathrm{C} 18: 2)$, vaccenic $\left(\mathrm{C} 18: 1_{\mathrm{i}}\right)$, stearic (C18:0), and palmitoleic (C16:1) fatty acids, followed by linolenic (C18:2) and myristic (C17:0) acids (Figure 2). Avocado oil was predominantly monounsaturated (Figure 2), while peanut oil was mainly polyunsaturated (Figure 4).

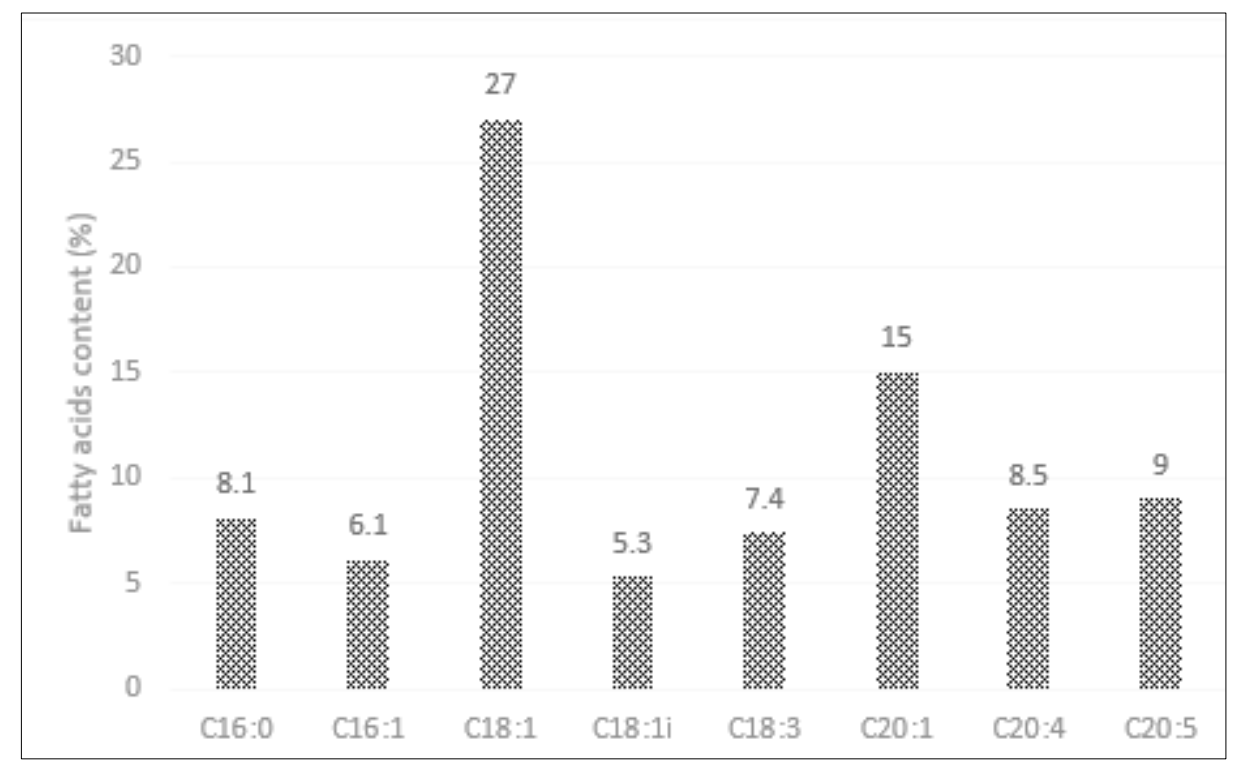

Figure 1. Fatty acids profile of peanut oil

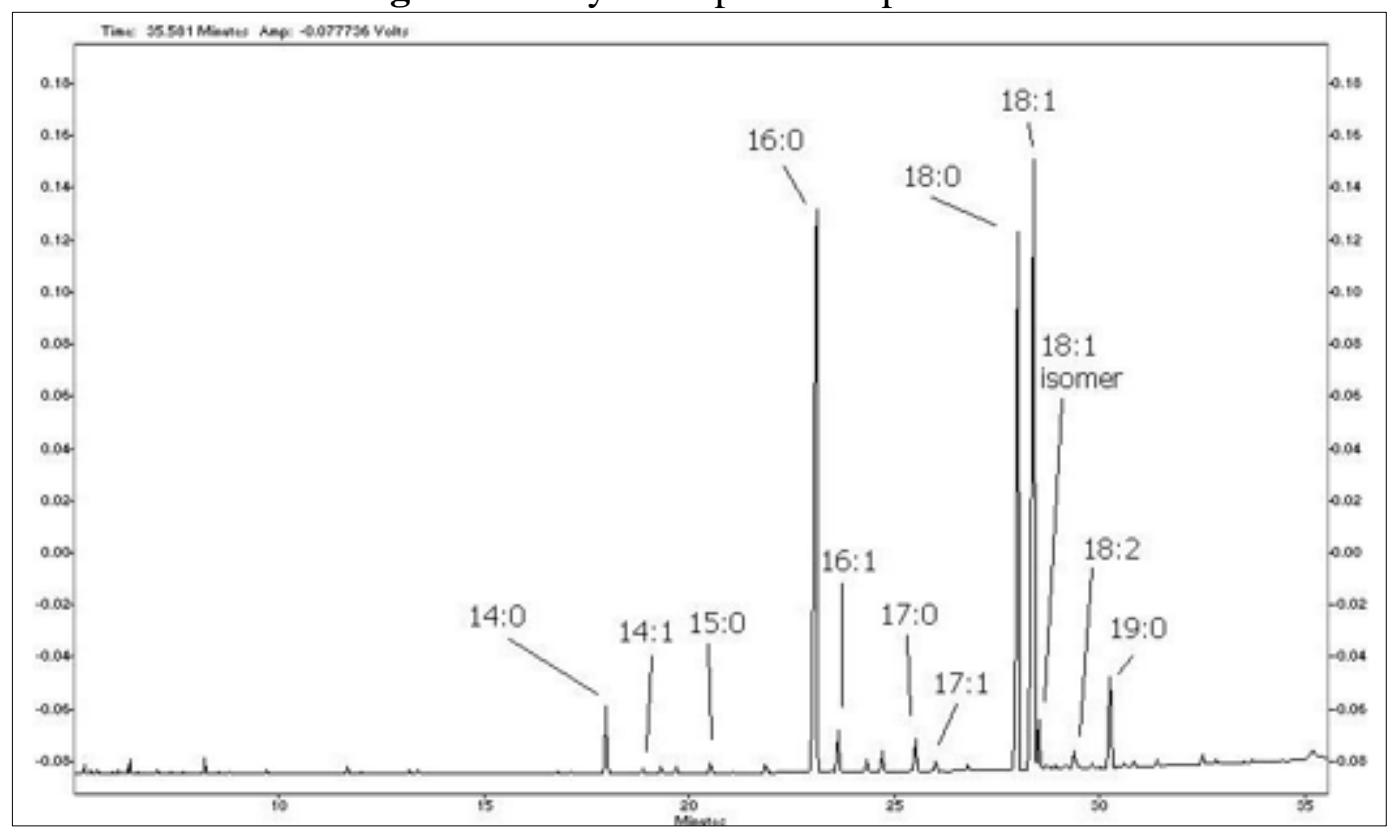

Figure 2. Chromatogram of unheated avocado oil 


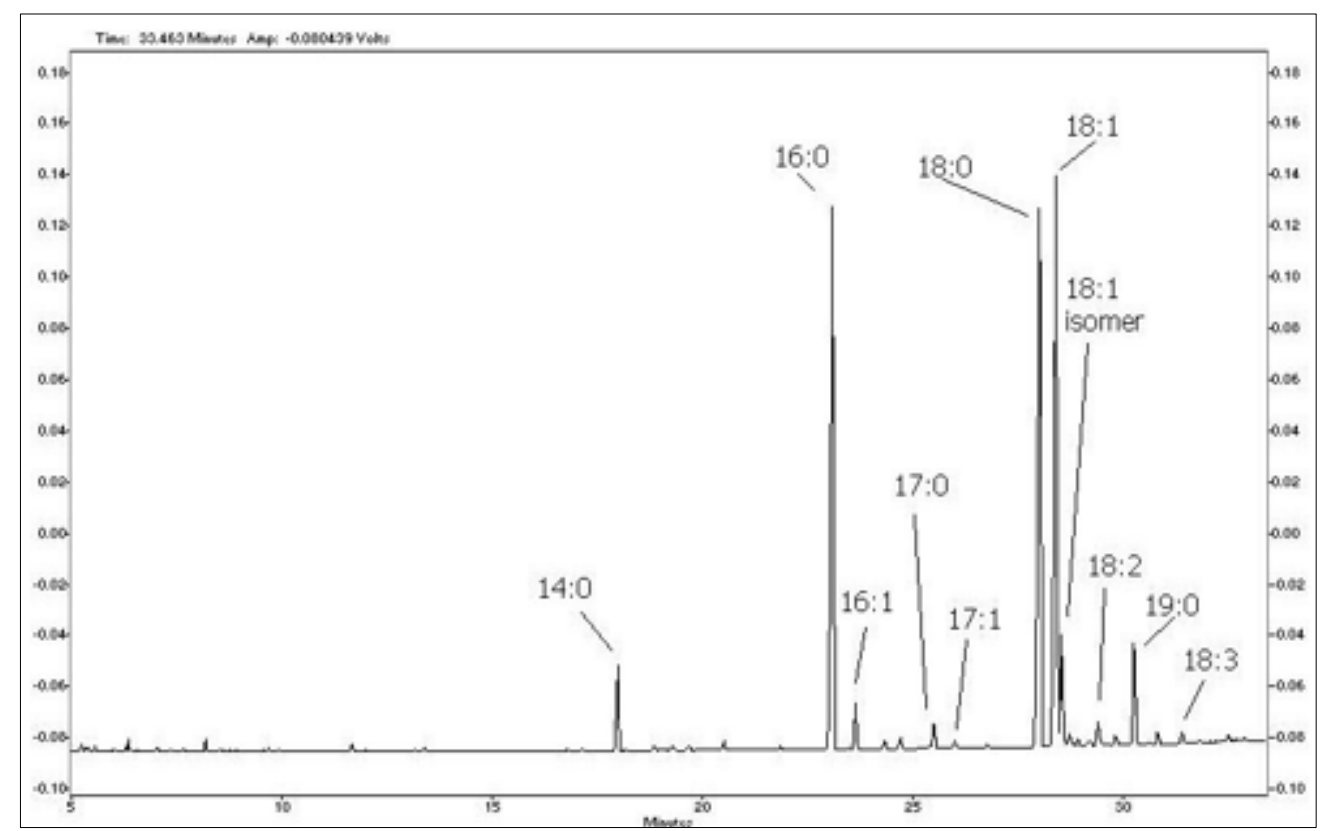

Figure 3. Chromatogram of avocado oil subjected to heating at $230^{\circ} \mathrm{C}$

Heating at a temperature of $230^{\circ} \mathrm{C}$, produced changes in the fatty acid profile for both oils. The most affected fraction by the heat treatment was the polyunsaturated fatty acids (PUFA), due to the high number of double bonds, which are more susceptible to oxidation (Figure 3, Figure 5). With high heating temperature, PUFA content decreased by $12 \%$ in peanut oil, and around $8 \%$ in avocado oil. The heat treatment of oils induced modifications of unsaturated fatty acids, these may undergo isomerization from cis to trans form. The fatty acid profile of the heated oils changed because of polymerization, cyclization, oxidation and other chemical reactions promoted by heat treatment.

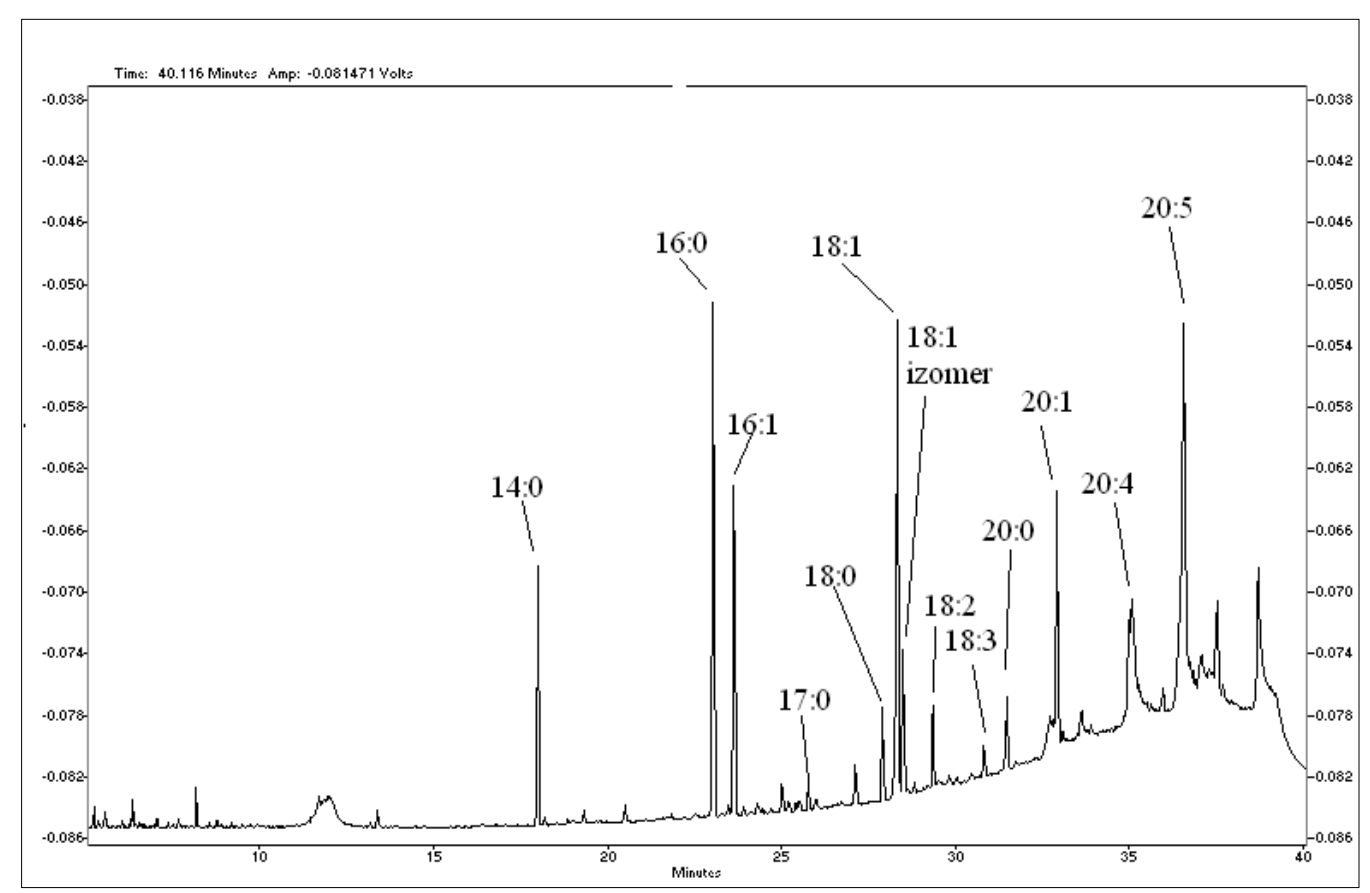

Figure 4. Chromatogram of unheated peanut oil 


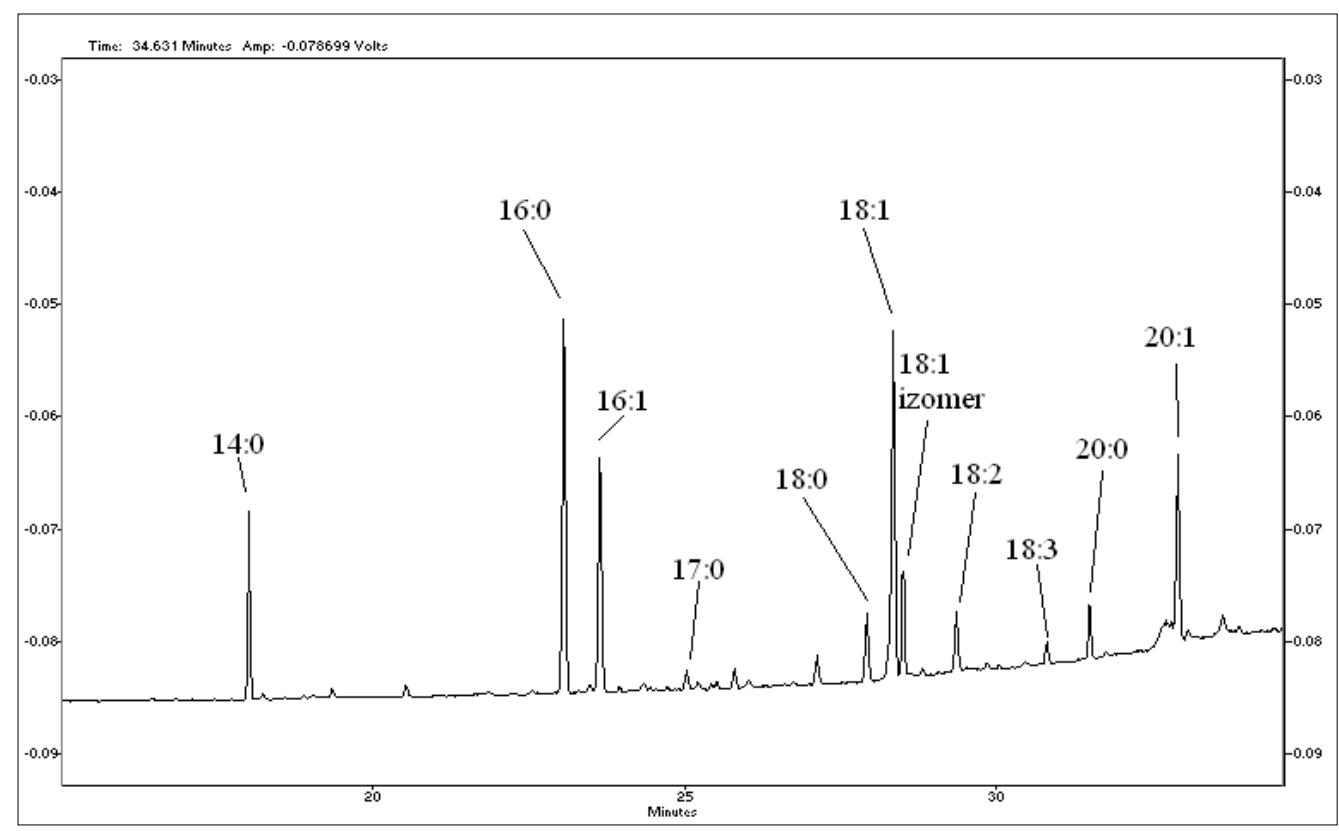

Figure 5. Chromatogram of peanut oil subjected to heating at $230^{\circ} \mathrm{C}$

\section{Conclusions}

Oxidation of lipids in vegetable oils varied with the heating temperature and type of oil. The peroxide index values of unheated oils were lower than those of oils subjected to heating. Peanut oil produced higher amounts of hydroperoxides, therefore was more unstable at heat treatment.

Avocado oil showed the smallest increase in thiobarbituric acid reactive substances and total polar compounds during the heat treatment. TPC was significantly influenced by heating temperature in both oils.

Statistical analysis of the data revealed that the increase in heating temperature up to $230^{\circ} \mathrm{C}$ significantly deteriorated the quality of peanut oil, but avocado oil was more stable.

Acknowledgments: This work was financial supported by Technical University of Cluj-Napoca in the framework of the GNaCARUT competition, research Contract no. 3015/2019.

\section{References}

1.TYAGI, V.K., VASISHTHA, A.K., J. Am. Oil Chem. Soc., 73, 1996, 499-507.

2.COSTA, C.A., CARLOS, A.S., GONZALEZ, G.P., REIS, R.P., Eur. J. Nutr., 51, 2012, 191-198.

3.WANG, S., MECKLING, K.A., MARCONE, M.F., KAKUDA, Y., TSAO, R., J. Agric. Food Chem., 59, 2011, 960-967.

4.VALANTINA, E., SAHAYARARAJ, S., PREMA, A., Rasayan J. Chem., 3, 2010, 44-53.

5.PAI, Z.P., KHLEBNIKOVA, T.B., MATTSAT, Y.V., React. Kinet. Catal. L., 98, 2009, 1-11.

6.WOOLF, A., WONG, M., EYRES, L., MCGHIE, T., LUND, C., OLSSON, S., WANG, Y., BULLEY, C., WANG, M., FRIEL, E., REQUEJO-JACKMAN, C., Avocado Oil, Alan R. Liss, Inc., New York, 2009, 73-125.

7.UNLU, N.Z., BOHN, T., CLINTON, S.K., SCHWARTZ, S.J., J. Nutr., 135(3), 2005, 431-436. https://doi.org/10.1093/jn/135.3.431

8.BRAI, B.I., ODETOLA, A.A., AGOMO, P.U., J. Med. Food., 10(2), 2007, 356-360.

9.NAYAK, B.S., RAJU, S.S., CHALAPATHIA RAO, A.V., J. Wound Care, 17(3), 2008, 123-126.

10.BERASATEGI, I., BARRIUSO, B., ANSORENA, D., ASTIASARÁN, I., Food Chem., 132(1), 2012, 439-446.

11.DING, H., HAN, C., GUO, D., CHIN, Y.W., DING, Y., KINGHORN, A.D., D’AMBROSIO, S.M., Nutr. Cancer, 61(3), 2009, 348-56. 
12.CREVEL, R.W.R, KERKHOFF, M.A.T, KONING, M.M.G, Food Chem. Toxicol., 38 (4), 2000, 385-93.

13.KATRAGADDA, H.R., FULLANA, A.S., SIDHU, S., CARBONELL-BARRACHINA, A.A., Food Chem., 120 (1), 2010, 59-65. https://doi.org/10.1016/j.foodchem.2009.09.070

14.NONTPRASERT, A., PUKRITTAYAKAMEE, S., NOSTEN-BERTRAND, M., VANIJANONTA, S., WHITE, N.J., Am. J. Trop. Med. Hyg., 62(3), 2000, 409-412.

15.WU, F., MAO, L., ZHUANG, P., CHEN, X., JIAO, J., YU, Z., Clin. Nutr., 39(12), 2020, 3703-3710. 16.QIYAN, Z., MINGMING, W., WENBIN, Z., WEI, Z., RUIJIN, Y., Food Chem., 311, 2020, $125-$ 134.

17.VOICA, C., IORDACHE, A.M., MIRICIOIU, M.G., MAGDAS, D.A., CRISTEA, G., Rev. Chim., 71(5), 2020, 283-289.

18.ALADEDUNYE, F.A., Eur. J. Lipid Sci. Technol., 116, 2014, 688-695.

19.CAPONIO, F., PASQUALONE, A., GOMES, T., Int. J. Food Sci. Technol., 38, 2003, 481-488.

20.KREPS, F., VRBIKOVÁ, L., SCHMIDT, S., SEKRETÁR, S., HÍREŠ, O., Eur. J. Lipid Sci. Technol., 116, 2014, 1685-1694.

21.FILIP, S., HRIBAR, S., VIDRIH, R., Eur. J. Lipid Sci. Technol., 113, 2011, 224-233.

22.BANU, M., PRASAD, N., SIDDARAMAIAH, N., Int. Food Res. J., 23, 2016, 528-537.

23.GHITEA, T.M., BUNGAU, S., TIT, D.M., PURZA, L., OTRISAL, P., CIOCA, L.A., PANTIS, C., LAZAR, L., Rev. Chim., 71(1), 2020, 335-342.

24.STOJANOVSKIM., ČAKAROVA, A., KUZELOV, A., JOSHEVSKA, E., DIMITROVSKA, G., TOMOVSKA, D., BOJKOVSKA, C., J. Agric. Plant Sci., 16, 2018, 103-112.

25.FARINES, M., SOULIER, J., RANCUREL, A., MONTAUDOIN, M.G., LEBORGNE, L., J. Am. Oil Chem. Soc., 72(4), 2000, 473-476.

26.LOZANO, Y.F., MAYER, D., BANNON, C., GAYDOU, E.M., J. Am. Oil Chem. Soc., 70(6), 1998, 561-565.

27.MCWATTERS, K.H., HEATON, E.K., J. Food Sci., 39(3), 1994, 494-497.

28.ALJUHAIMI, F., ÖZCAN, M.M., J. Food Proces. Preserv., 42(2), 2018, 13462-13469.

29.SHI, R., GUO, Y., VRIESEKOOP, F., YUAN, Q., ZHAO, S., LIANG, H., Eur. J. Lipid Sci. Technol., 117(7), 2015, 1008-1015.

30.LIU, X., JIN, Q., LIU, Y., HUANG, J., WANG, X., MAO, W., WANG, S., J. Food Sci., 76(3), 2011, 404-412.

31.DONG, X.Y., ZHONG, J., WEI, F., WU, L., LEI, Y., LIAO, B.S., QUEK, S.Y., CHEN, H., J. Am. Oil Chem. Soc., 92(2), 2015, 233-242.

32.POP, F., Studia UBB Chem., 63(2), 2018, 43-52.

33.SEMENIUC, C.A, MANDRIOLI, M., RODRIGUES-ESTRADA, M.T., MUSTE, S., LERCHER, G., Eur. Food Res. Technol., 242, 2016, 431-439.

34.SANTANA, I., TORRES, A.G., LOURDES, M.C., SUELY, C., Eur. J. Lipid Sci. Technol., 117(7), 2014, 999-1007.

35.BOGATU, L., DRAGOMIR, R.E., ROSCA, P., Rev. Chim., 67(1), 2016, 14-21.

36.SUN-WATERHOUSE, D., THAKORLAL, J., ZHOU, J., Int. J. Food Sci. Technol., 46(8), 2011, 1575-1585.

$\overline{\text { Manuscript received: } 6.05 .2021}$ 